\title{
Recurrent cough and hemoptysis associated with tracheal capillary hemangioma in an adolescent boy: $A$ case report
}

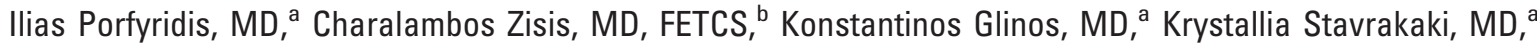 \\ Dimitra Rontogianni, MD, ${ }^{\mathrm{c}}$ Spyros Zakynthinos, MD, ${ }^{a}$ Charis Roussos, MD, PhD, FCCP, and \\ Grigoris Stratakos, MD, athens, Greece
}

$\mathrm{T}$ racheal tumors are rare and more frequently malignant in adults, whereas they are more frequently benign in children. Hemoptysis often complicates tracheal neoplasms, especially malignant ones, or can be a presenting symptom. Common benign tumors are chondroma, papilloma, and fibroma, most often occurring in the upper one third of the trachea in children and the lower one third in adults.

Simple radiologic studies and standard endoscopy are usually sufficient for almost all tracheal tumor diagnoses. Interventional bronchoscopic techniques can treat benign and inoperable malignant lesions, avoiding more aggressive surgical approaches. We present here the diagnosis and management of a rare, benign tracheal tumor.

\section{Clinical Summary}

A 17-year old boy had cough and hemoptysis (about $100 \mathrm{~mL}$ ) on admission day. He reported recurrent hemoptysis during the past year. There was no history of foreign body aspiration, dyspnea, dysphagia, hoarseness, trauma, and intubation or airway endoscopy. Lung and heart physical examination showed no abnormalities and results of the routine oronasal cavity examination were unremarkable. Laryngoscopy disclosed blood coming from the trachea. All standard hematologic and chemical laboratory tests were within the normal range, as were findings on the chest radiograph and spiral computed tomographic scan. Perfusion scanning was negative for pulmonary embolism. Examination with a flexible bronchoscope revealed two cherry-red polypoid tracheal masses, about $0.4 \mathrm{~cm}$ in diameter (Figure 1, A), arising from the left anterolateral wall of the trachea in the upper one third, one below the other, with fresh blood on the surface. To avoid potential massive tumor bleeding during biopsy, we scheduled a procedure with a rigid bronchoscope.

Using a 12-mm Storz tracheoscope (KARL STORZ GmbH \& Co. KG, Tuttlingen, Germany), with the patient under total intravenous anesthesia, we coagulated these polypoid lesions with

From the Critical Care and Respiratory Division, ${ }^{\text {a }}$ University of Athens; and Departments of Thoracic Surgery ${ }^{\mathrm{b}}$ and Pathology, "Evangelismos" Hospital, Athens, Greece.

Received for publication June 21, 2007; accepted for publication July 19, 2007.

Address for reprints: Charalambos Zisis, MD, FETCS, "Evangelismos" Hospital, 45-47, Ipsilantou str, 10676 Athens, Greece (E-mail: chzisis@ hol.gr).

J Thorac Cardiovasc Surg 2007;134:1366-7

$0022-5223 / \$ 32.00$

Copyright $\odot 2007$ by The American Association for Thoracic Surgery doi:10.1016/j.jtcvs.2007.07.014 electrocautery and excised them with the rigid forceps, producing only minor trauma and bleeding. After removal of the protruding masses, the mucosal basis was further coagulated with the electrocautery forceps via the flexible videobronchoscope passing through the rigid tube (Figure 1, $B$ ). The whole procedure lasted less than 30 minutes and was totally uneventful. No late complications or morbidity resulting from the treatment were noted. Histologic examination revealed numerous capillaries arranged in a lobular pattern and the presence of a feeding vessel (Figure 2, A). No malignant cells were observed in the tumors. The overlying epithelium was intact. Immunohistochemical analysis was positive for CD31 and CD34 antibodies (Figure 2, B), showing endothelial cells, and endocrine neoplasm angiogenesis (CD56-, synaptophysin-) was excluded. The diagnosis was lobular capillary hemangioma $(\mathrm{LCH})$ of the lower respiratory tract. The patient was discharged the day after and remained completely asymptomatic thereafter. On the 6-month follow-up bronchoscopic examination, no relapse or other abnormality was observed except for a small $(<0.2 \mathrm{~cm})$ scar on the previous biopsy site, proven granulomatous on pathologic examination. No further symptoms or findings have been reported on bronchoscopic studies during more than 12 months of follow-up.

\section{Discussion}

In adults, the most frequent causes of hemoptysis are infectious diseases, malignant tumors, cardiovascular disorders, and other inflammatory diseases. LCH has seldom been reported, and never in an adolescent.

LCHs are benign tumors with distinctive lobular capillary arrangement. Histopathologically, LCH was previously termed "pyogenic granuloma," although it is not caused by infection nor is it true granuloma. ${ }^{1}$ The term "lobular capillary hemangioma" has recently been introduced to accurately describe these lesions. Typically elevated and red to purple in color, they consist of a proliferation of capillary-sized vessels lined by flattened endothelium. They are generally multiple, often involving the upper respiratory $\operatorname{tract}^{2}$ aside from the skin. In the English literature, 3 adult cases with hemoptysis resulting from tracheal LCH were found and 1 with bronchial location. ${ }^{2-5}$

The commonest presenting LCH symptoms are bleeding and obstruction in the case of the nasal cavity. Pain is not typical.

In the case reported, the lesion was discovered while we were searching for causes of nonspecific clinical symptoms, such as cough and hemoptysis. Because of negative chest radiographic and spiral computed tomographic findings, bronchoscopy was indicated and led us to the tracheal $\mathrm{LCH}$ diagnosis. At early detection, such lesions are small and may be treated endoscopically with low morbidity, as in our case. The endoscopic appearance is nonspe- 

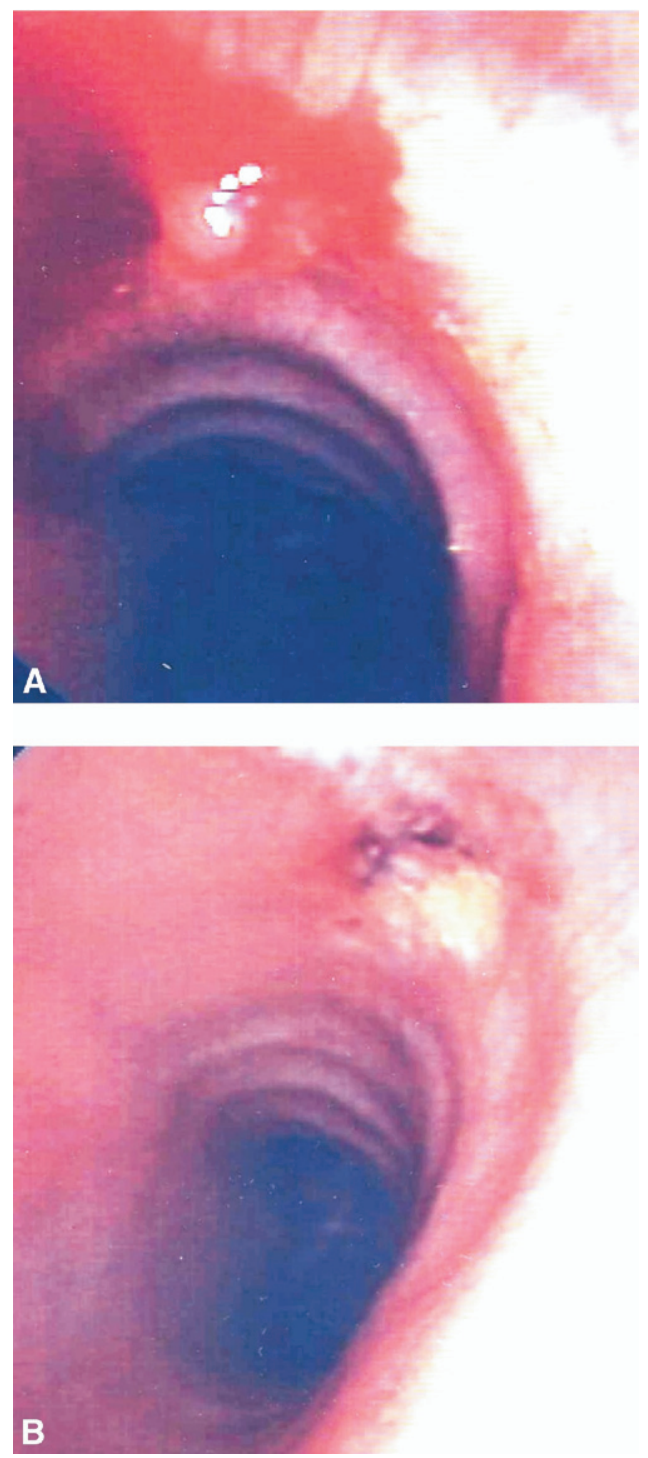

Figure 1. A, Endoscopic view of the left anterolateral wall of trachea showing two polypoid tracheal masses about $0.1 \mathrm{~cm}$ and $0.3 \mathrm{~cm}$. B, Posttreatment view of the same area. There is no relapse or other abnormality except from a small $(<0.2 \mathrm{~cm})$ scar on the site of previous cauterization.

cific and could mimic cystic adenoid carcinomas, adenomas, and carcinoids. However, these lesions can often cause serious hemorrhage, disturbing central airway patency. Given the patient's young age and the negative diagnostic workup, no major surgical intervention was considered before a firm diagnosis was made. For safety reasons, a rigid bronchoscope rather than a flexible one was used, and the tumor was finally removed successfully with a rigid forceps and electrocautery.
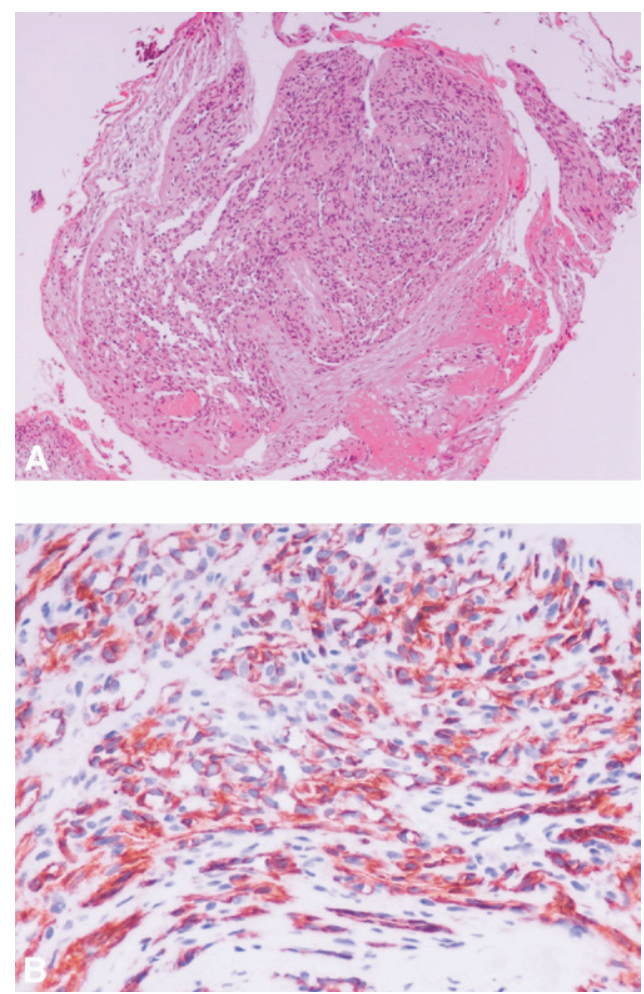

Figure 2. A, Patient's histopathologic specimen. Numerous capillaries arranged in a lobular pattern. The endothelial cells were normal and the overlying epithelium was intact (hematoxylin and eosin; original magnification $\times 50$ ). $B$, The endothelial cells showed positive immunohistochemical reaction to anti-CD31 antibody (EnVision; original magnification $\times 400$ ).

Although rare, $\mathrm{LCH}$ should be considered as a possible benign cause of hemoptysis and cough, amenable to conservative endoscopic treatment. No decision for a radical surgical approach should be made on endoscopic appearance before conclusive histopathologic diagnosis.

\section{References}

1. Mills SE, Cooper PH, Fechner RE. Lobular capillary hemangioma: the underlying lesion of pyogenic granuloma. A study of 73 cases from the oral and nasal mucosal membranes. Am J Surg Pathol. 1980;4:470-9.

2. Irana S, Brack T, Pfaltz M, Russi FW. Tracheal lobular capillary hemangioma: a rare case of recurrent hemoptysis. Chest. 2003;123: 2148-9.

3. Madhumita K, Sreekumar KP, Malini H, Indudharan R. Tracheal haemangioma: case report. J Laryngol Otol. 2004;118:665-8.

4. Zambudio AR, Calvo MJ, Lanzas JT, Medina JG, Paricio PP. Massive hemoptysis caused by tracheal capillary hemangioma treated with interventional radiology. Ann Thorac Surg. 2003;75:1302-4.

5. Strausz J, Soltesz J. Bronchial capillary hemangioma in adults. Pathol Oncol Res. 1999;5:223-4. 